$\left.\begin{array}{c}\text { INTERNATIONAL JOURNAL OF } \\ \text { ORGANIZATIONAL LEADERSHIP }\end{array}\right) \begin{gathered}\text { INDUSTRIAL } \\ \text { MANAGEMENT } \\ \text { INSTITUTE }\end{gathered}$

\title{
Developing leadership competencies: Insights from emergent junior talent-in- transitions in South Africa
}

\author{
MacDonald Kanyangale*, Noel Pearse \\ Rhodes Business School, Rhodes University, Grahams town, South Africa
}

\begin{abstract}
Keywords:

Leadership Development, Leadership Development Assessment, Management Development, Portfolio Assessment

Correspondence:

M.Kanyangale@ru.ac.za

Increasingly, leadership development programs are being challenged to produce robust evidence of their impact on leadership competencies of participants in South Africa. If used properly, portfolio assessment of one`s own leadership development journey has the potential to depict not just learning achievement, but also leadership growth and development. A multinational corporation in South Africa outsourced to a business school a program to develop leadership of selected 15 high-performing employees who were in transition to junior management. To the end of this study, qualitative research was conducted to get a complex and detailed understanding of how these participants perceived and self-assessed their own development of a self-selected set of leadership competencies over a period of time using portfolios. As the number was small, all the 15 personal and professional development portfolios were collected and analyzed using open coding and constant comparison techniques to induce themes. Evidence in the portfolios showed that while emergent junior talents were able to identify specifically the leadership competencies they were developing, they actually had difficulties to capture strong, relevant, and dynamic pathways of how their leadership competencies evolved and developed over time. More importantly, evidence in the portfolio revealed that the internal reward system was less supportive as it valued individual achievement of own performance target even at the expense of supporting others to develop their leadership. The lack of support from mentors and colleagues stifled leadership development of participants. This paper argues that it is vitally important that an organization's own systems are integrated and coherent enough not to inadvertently impede leadership development efforts.
\end{abstract}




\section{Introduction}

Many stakeholders, in particular leadership development practitioners, leadership development participants, and organizational leaders in South Africa are disappointed that despite massive investment and faith in leadership development programs (LDPs), results are disappointing and unsatisfactory. In most organizations, there are insufficient, unsteady, and less diverse leadership pipelines. Above all, these leadership pipelines fail to reflect the diversity, namely gender, race, and ethnicity of the overall employee population in postapartheid South Africa.

It is important that key employees in an organization are equipped with leadership as a way of developing talent and bench strengths. Leadership requirements differ with levels of ascending complexity of demands along the leadership pipeline (Charan, Drotter, \& Noel, 2001; Conger \& Fulmer, 2005; Freeman, 2011; Kaiser, 2011; Zaccaro, 2001). This invokes scholarly impetus to examine the type of evidence which LDP participants at various stages in the pipeline (e.g. executive, middle management and junior management) actually provide to confirm and elaborate on how they can develop their leadership competencies or not. This makes assessment of leadership development a very interesting issue.

Collins and Holton (2004, p. 232) argued that "research on effectiveness of leadership development is sparse”. In a similar vein, Day, Harrison, and Halpin (2009) claimed that we know little about program effectiveness related to leadership development. This gap is potentially very startling for researchers and practitioners; as a result, a great deal of research on leadership has emerged overtime.

Highly successful organizations focus on developing and assessing a set of leadership competences at various levels of an organization. Emergent junior talent is a very interesting group moving up into the first-level of management. Simultaneously, this group also moves up into leadership positions such that they truly require firm bedrock before being faced with the significant shift in role, identity, and function (Benjamin \& O’Reilly, 2011; Carden \& Callahan, 2007). This unique transition of employees is often characterized by changes in self-concept and perspectives, moving away from identifying with their peers to primarily identifying with the organization and managing former peers; and also new challenges beyond extant level of experience (Kaiser \& Craig, 2011). Instead of doing the work themselves, first line managers begin to assume responsibility for supervision and the performance of others who carry out the day-to-day work of an organization (Kaiser, Craig, Overfield, \& Yarborough, 2011). While these supervisory employees still require good 
technical skills, the work demands more supporting incumbent in terms of interpersonal and conceptual skills -albeit less than what is demanded at more senior levels (Kaiser, Craig, Overfield, \& Yarborough, 2011; McCauley, Moxley, \& Van Velsor, 1999).

Holistic leadership development requires a combination of various learning modes, namely experiential learning and reflection-as-learning in different contexts, classroom learning, on-the-job and developmental activities, and also organizational mechanisms (Quatro, Waldman, \& Galvin, 2007; Weindling, 2003). Louw, Pearse, and Dhaya (2012) claimed that both formal and informal learning methods and structured activities are all useful for development of leadership competencies. However, knowledge on best ways within the formal and informal learning methods to prepare and develop high potential employees is sparse (Davis, Darling Hammond, LaPointe, \& Meyerson, 2005).

In a large multinational in South Africa, an eleven month LDP was designed to prepare a selective group of high-performance employees (also known as emergent junior talent) for future positions of leadership. Participants were identified and selected from different departments by the company as part of a talent management program for junior level managers. The main research question of this qualitative study was how emergent junior talents which went through a LDP assessed themselves using a portfolio of evidence to demonstrate or reflect how they had developed (or not) on their self-selected leadership competencies during the duration of the LDP.

This study is unique in two ways. Firstly, it privileges the viewpoint of emergent junior talent that went through a LDP as the best source for in-depth understanding of how leadership develop or fail to develop at the entry-level to management. Secondly, it uses selfassessment as a tool to allow an emergent junior talent-in-transition to meaningfully draw together multiple sources of evidence to provide robust insights on how their leadership development occurred or not at this level. This is invaluable as Manderscheid (2008) rightly stresses that there is a paucity of empirical research documenting the impact of leadership development intervention especially early in a leader`s transition.

This paper starts with a discussion of the three key principles underpinning this LDP. Subsequently, the paper turns to the discussion of self-assessment and portfolio assessment. Thereafter, the paper discusses the research method that was used in this study. This is followed by presentation of the findings of the study in detail. Finally, the paper concludes by highlighting implications of these findings on how to develop leadership competencies and areas for potential future research are highlighted. 


\section{Principles Underpinning the Leadership Development Program}

Three principles which underpinned this LDP are worth highlighting. Firstly, each emergent junior talent in this LDP was required to select a mentor within the organization. A mentor was assumed not only to help the participant develop a clear, realistic, personal, and professional development plan, but also regularly meet with their mentee to monitor developmental progress, provide feedback, and support them as they work through frustrations and mistakes in their work.

Secondly, emergent junior talents had discussions with their respective mentors to ultimately self-select and prioritize three of the eight leadership competencies to be developed over the 11 months of the program. Day, Harrison, and Halpin (2009) argued that the design of leadership development program should account for individual differences. Notably, each emergent junior talent also used feedback from annual performance appraisal to gauge current performance and uncover gaps which were centralized in this leadership development journey. Thus, development is not entirely fortuitous, but rather goal-oriented and requires clear understanding of available and desirable potentials and specified levels of leadership competencies (Avolio \& Chan, 2008). The conundrum on the concept of competence is beyond the scope of this study. It should be noted that the term competence is derived from the word "iknoumai" which means to arrive or having the ability to achieve something (Mulder, Weigel, \& Collins, 2006). With this root, Jauhari (2006, p. 123) is explicit to define competency as "a combination of observable and applied knowledge, skills, and behaviors that create a competitive advantage for an organization".

Sparrow (2002) dichotomizes competence as baseline (what should), in terms of measures of acceptable behavior and performance; while inspirational ideals (what could) refers to effective and superior performance. Additionally, competence is also dichotomized into individual behavioral competence on one hand and organizational competence on the other hand (Bolden \& Gosling, 2006). Simply put, competencies represent a synthesis of a variety of skills, technologies, and knowledge streams that generate competitive advantage for an organization (Boyatzis, 1982).

The large multinational which initiated this program has a leadership competence model which pronounces competencies as characteristics that differentiate average from outstanding performance in a specific role, job, organization, or culture. This leadership competence model was useful in creating and promoting common language for discussing capabilities and performance. Generally, leadership competence framework helps employees identify 
behaviors, and what they need to know and do to achieve target outcomes, but also prepare for future responsibilities (Chung-Herrera, Enz, \& Lankau, 2003; Gordon, 2003).

Thirdly, each emergent junior talent in this LDP developed an action plan which he or she was expected to implement over a period of time to develop the identified leadership competencies, and also collect valid evidence from a variety of sources to critically reflect on progress that was made and challenges encountered. In the development plan, each emergent junior talent specified a range of relevant activities and their deadlines for execution. The developmental activities were all aligned to each of the three self-selected leadership competencies. At the end of the program, each participant submitted a portfolio for assessment of their leadership development. Day (2010, p. 42) underscored that "it is not the quantity or quality of the experience that matters in the long term development of skill; rather it is a direct function of the amount of deliberate practice that is undertaken over a considerable period of time". According to Revans (1983, p. 54) 'there can be no learning without action and no (sober and deliberate) action without learning”. Cognizant of the temporal dimension of leadership development, Dixon (1993, p. 248) suggests:

"Development occurs over time. Time is needed to act, to see the results of one's action, to talk with others, to gain perspective, to review theory that might inform one's thinking, to act again, to reflect again, to let go of old ideas and try anew”.

It is absolutely critical that scholars of leadership development explicitly expound on what development is all about. First and foremost, development differs from training which is essentially about "procedures and processes used to teach proven solutions to known problems” (Day, Harrison, \& Halpin, 2009, p. 129). It should be mentioned that development entails “altering one’s way of making meaning”, and enhancing "individual`s capacity for being able to quickly make sense of the environment and adapt effectively by learning their way out of problems” (Day, Harrison, \& Halpin, 2009, p. 129). To understand development, there is a need to link evolving actions to interactional outcomes in order to depict process which explains why and how things change, stay the same, and regress or progress. Ontologically, leadership development focuses on a social relational process (Avolio, Walumbwa, \& Weber, 2009), which is distinctive from "leader development" whose focus is the individual who is a leader (e.g. development of intrapersonal aspects in form of human capital; what leaders do and their behavioral outcomes). In brief, leadership development 
refers to "a function of between-individual process [and] involves the creation of social capital primarily at the group, team, and organizational level” (Day, Harrison, \& Halpin, 2009, p. 159).

\section{Self-Assessment}

Leadership development can be assessed by externals (e.g. direct reports, peers, superiors, clients etc.), self, or a combination of these. With reference to self-assessment, Mann (2010) posits three coexisting perspectives. First, self-assessment is seen as ability. In this view, it is “(implicitly or otherwise) a personal unguided reflection on performance for the purposes of generating an individually derived summary of one's knowledge, skill, and understanding in a particular area” (Eva \& Regehr, 2008, p. 15). The second is the view of self-assessment as encompassing self-directed assessment-seeking behaviors and reflection which are viewed as important pedagogical strategies. From this perspective, the participant accepts personal responsibility of searching for information from external sources that can be used for performance improvement (Mann, 2010). Examples of external sources include 360-degree assessments, testimonials, coaching reports and, performance reviews. Thirdly, selfassessment is seen as self-monitoring, the minute by minute assessment of how someone is doing at a task during its performance, which may lead to immediate corrective behavior or even the identification and adoption of alternative approaches (Eva \& Regehr, 2008). It is not only the self-monitoring aspect, but also the "self-directed assessment-seeking behaviors and reflection" which makes portfolio assessment useful to stimulate reflective development towards a goal (Bell \& Federman, 2010; Moskal, 2010). Therefore, it is imperative to take a bird's eye view of portfolio assessment.

\section{Portfolio Assessment}

Portfolio is an ideal instrument for assessment of development or learning that occurs over a relatively long period of time (McMullan, 2006; McMullan et al., 2003). In essence, portfolio has been used as a learning and assessment tool for reflective practice and also to uncover the thinking behind the performance (Borko, Michael, Timmons, \& Sidle, 1997). Generally speaking, a portfolio is a purposeful collection of various forms of evidence representing learners' learning, progress towards a goal, or achievement over time (Driessen, Van Tartwijk, Vermunt, \& Van Vleuten, 2003; McMullan, 2006). Simply put, portfolio is “a tangible record of what someone has done” (Redman, 1994, p. 11). More importantly, it is 
more than mere provision of evidence as it reflects a dynamic record of growth and professional change. Briefly speaking, portfolio assessment allows learners not only to demonstrate "know-what" and "know-how", but also "know-why" through reflection on their own goals, actions, and initiatives taken to direct their own professional development and growth (Mittendorff, Jochems, Meijers, \& Den Brok, 2008, pp. 76-78).

In addition to being a record of achievements and a tool to develop self-reflection, a portfolio also leads to awareness of the learners' own skills, strengths and limitations, as well as developmental needs. In this way, a portfolio is used to inform as well as transform the learner (Borko, Michael, Timmons, \& Sidle, 1997). Malik (1993) cautions that portfolio assessment should not be about assessing learners' ability to write about their practice or experiences, but rather the standard of what they actually are able to do or practice and also how the learner is transformed.

\section{Method}

This qualitative study seeks to gather multiple perspectives of reality to understand how emergent junior talent-in-transitions perceived and self-assessed their development of leadership competencies through a portfolio during a LDP. Emergent junior talents in this LDP were purposively identified by the organization for being high potential employees moving into leadership positions at the entry-level of management. As the number of participants in this LDP was relatively small, all the portfolios produced were included in this qualitative study. A total of 15 personal and professional development portfolios were actually collected and analyzed. As an inductive study, open coding and constant comparison techniques were employed to induce themes from data in each portfolio. Subsequently, these themes were further compared constantly across portfolios to develop broader and conceptual themes reflecting similarities in the evidence of how emergent junior talent-in-transitions assessed their leadership development. Size of each portfolio ranged from 12 to 27 pages. Evidence provided was mainly in the form of narratives about critical incidents, testimony from customers, peers, bosses, and also emails. It is purely for ethical reasons that the name of the South African corporate and any telling details are withheld. Predominantly, the use of frequency on themes should not be misconstrued as statistical analysis, but rather as a matter of presentation to portray the flavor or variety of the findings as a whole. 


\section{Results}

Six various themes were delineated from how emergent junior talents assessed themselves and depicted evidence of how they developed (or not) their leadership competencies. The six emergent themes are (a) leading self in a sink or swim climate; (b) unclear pathways of developing leadership; (c) developmental tasks misaligned with leadership competence intended to develop; (d) exploiting developmental power inherent in performing a different task. Additionally, there is also evidence of (e) conceptual leadership development; and (f) developing by developing others. Table 1 presents these various themes induced from evidence contained in the portfolios of emergent junior talent-in-transition.

Table 1

Themes in Evidence of How Emergent Junior Talents Assessed themselves on Leadership Competence Development

\begin{tabular}{lc}
\hline Themes in the evidence & Frequency \\
\hline Leading self in a sink or swim climate & 11 \\
Unclear pathway of developing leadership competencies & 10 \\
Developmental tasks misaligned with leadership competence & 10 \\
Exploiting developmental power inherent in performing a different task & 9 \\
Conceptual leadership development & 3 \\
Developing by developing others & 1 \\
\hline
\end{tabular}

\section{Leading Self in a Sink or Swim Climate}

Eleven of the emergent junior talents experienced difficulties to lead themselves as they were consumed by self-doubt arising from the lack of support. Some of these wrote about how people were competitive and goal-oriented that mentors lacked time to meet mentees to periodically review implementation progress. Other emergent junior talents-in-transition were not able to prolong relationship with their mentors due to undermining or condescending immediate managers. A variety of competing priorities of mentors and managers in the corporate environment placed greater value on meeting of immediate business goals rather than rendering support to LDP participants. For example, one of the emergent junior talents expressed:

My mentor is a good person. We have known each other since high school. He works at head office. The problem was that I am based in Durban. We simply cannot meet. Every time I went to head office I tried to check him and set a meeting. But this was not possible. 
Coincidentally, he was always travelling to visit clients whenever I was at head office. He had to perform and achieve his target which was his priority in order to get a bonus or promotion. At work, my boss was busy as we have lost clients who have not renewed their contracts with us... this was a threat to our survival. There was no one to assist me (MDPP3).

It was notable that very few of the emergent junior talents distinguished themselves by adopting a sense of high self-efficacy, control and responsibility for self-monitoring, and reflection-as-learning to develop own competencies. One of these emergent junior talents depicted herself as an isolated, abandoned, but self-directed, persistent learner with internal locus to achieve, illustrated as follows:

As with my boss, he made it clear that his priority was to get or retain clients. He was blunt that he had no time for me. This always made me realize that I am on my own but had to push on and write something ... had to follow my plan and monitor it knowing fully well that I had no one to talk to about my development plan ... no one to give me any feedback or guidance whatsoever. It could be better with feedback, but this is how I implemented my development plan and pursued my development journey. I was determined to chart my own career path in or outside this company (MDPP6).

\section{Unclear Pathways of Developing Leadership Competencies}

Ten of the fifteen emergent junior talents were not able to fuse together robust and interconnected evidence to portray pathways (e.g. stages or phases, sequences or shifts in level and variety of competencies) of leadership competence development over time. Instead, most of them provided numerous, discrete, and snapshots of evidence from immediate superior, customers, and peers. Commonly, this type of evidence was not sufficiently reflected upon by emergent junior talents to intricately interweave details, lay bare the multiple and dynamic ways in which levels of competence evolved, remained the same or regressed as they encountered leadership development opportunities and challenges. Snapshots of evidence in the portfolio of most emergent junior talents illustrated failure to track interconnection of evidence to a range of developmental experiences or interrelationship of past activities (e.g. unexpected or planned) to the present reality; and consequently, depict what cumulatively led to the level of competence that was being 
captured in many of the different sources of evidence. Below is an excerpt of an email from a superior of one of the emergent-junior talents which praises the networking and helpfulness of a subordinate. However, the portfolio of this emergent junior talent was not clear about how the manifested competences were actually developed:

She is a very committed employee and uses her contacts and network in the company to navigate through the organization to solve issues, pursue identified opportunities and get results. She is also helpful to new employees, helps them to settle down ... guides them on what is expected ... she know most of the things here (MDPP 9).

In a similar vein, another emergent junior talent singled out a one-off incident which could not adequately depict a process, pattern or series of formative conditions, interrelated actions and their consequences as scaffolds or solid building blocks underlying the competence of leading self to execute decision and deliver on promise:

Just recently, I was overseeing a situation where I made key decisions on my own to assist a customer who had [nature of problem deleted].Even though we did not have [name of product] in stock in the country, an alternative solution was found by way of having a demo training product striped off [name of product] and supplied to the customer in no time. I was in consultation with all internal stakeholders and gave them feedback all the time. I feel I decided and acted swiftly, delegated well and gave feedback well that the customer was happy (MDPP 4)

The extract below is from an email of a superior of one of the emergent junior talent-intransition, presenting evidence of having demonstrated integrity, executing, and delivering results. Clearly, this emergent junior talent did not reflect and compare her current performance with what she was targeting, whether or how this was narrowing or widening the gap between the two. Consequently, her thoughts were not provided to portray how she actually attained the level of competence reported by her superior in the following extract:

She demonstrates integrity in her role in the [name of department deleted] aligning her values with the company values. She uses her extensive network of key role players in the 
organization very well to solve problems and delivers results to customers. She delivers on her promise and keeps a customer orientation as a focal point of her actions (MDPP11).

In exceptional instances, a few of the emergent junior talents provided detailed evidence which included deeper insights of the self and latent abilities that were discovered through reflexive dialogue with their bosses, peers, and colleagues. One emergent junior talent wrote about how she was stretched by activities of leading others and staying in the limelight:

In one of the progress review meetings, my new manager praised my contribution to the new department that I had just joined. He noted that I am knowledgeable about many aspects of our business, but I am quiet and very shy. He advised me to be out there and be noticed ... make contribution and lead others. I was given a chance to chair several meetings ... in the department ... lead others ... make presentations. It was discomforting at first...I would take a lot of time to familiarize myself with what I would present ... gradually I started feeling comfortable about being in the limelight. Later on my manager decided that I present at manager's meeting. I do that these days. I do not have to be shy and remain in the shadow anymore ... my boss is pushing for more ... (MDPP7).

\section{Developmental Tasks Misaligned With Leadership Competence}

Nine of the fifteen emergent junior talent-in-transitions had difficulties to align tasks they pursued on one hand, and the type of specific leadership competence which they were developing. One of evidences tendered by his good task execution depicts the development of an interpersonal competence supporting others to achieve top performance. In a similar way, another emergent junior talent-in-transition illustrated how timely execution of activities to organize corporate events could be evidence of developing the social competence of supporting others to top performance:

I was a stand-in for my colleague who was involved in an accident. I was involved in corporate ... sponsorship ... organizing events. I always made sure invitations were emailed in good time ... venue was booked, inspected and branded. This has developed my competence to demonstrate and support others to top performance ... (MDPP 3). 
On a different leadership competence, another emergent junior talent misconstrued her supportive role in organizing an ethical training as an activity that could contribute to the actual development of her own ethical competence to "perform to ethical standards".

I assisted with arrangements for a visiting team of experts on ethics who came to our company. I had to arrange a driver to transport the team, booked the venue and catering for the trainings. I managed to handle all stressful situations and the trainings were smooth and successful. This is how I developed my competence to perform to ethical standards and taking responsibility (MDPP 6).

Conversely, very few emergent junior talents actually stood out for properly aligning tasks which they pursued with leadership competencies. In this regard, one emergent junior talent aligned the competence of "driving innovation, change and continuous improvement" with evidence of specific activities such as promotion of new idea generation to solve identified problems.

The idea of a viewing system will enable cash collectors and customer care agents to timely see whatever deposits have been made at the bank by a customer...Customer care centre will be able to properly assist the customers with queries ....customer error of depositing their cash in a wrong account will be easy to see and trace. Everyone will have up-to date statements, deal with queries in timeous manner. When I presented this to management the first question was how much this will cost? I was told the idea was good, but there was no money. The second meeting went well as I had all the supporting information required at my disposal. I talked to everyone involved with this. The idea is accepted, it is new, good and better for all of us (MDPP 14).

\section{Exploiting Developmental Power Inherent in the Different Task}

Predominantly, evidence in the portfolio of ten emergent junior talents focused on three aspects, namely nature of developmental opportunity (e.g. lateral moves such as stand-in for a colleague, job rotation; new assignment; participation in cross functional meetings etc.); duration of opportunity to perform a task different from what one was already doing; and variety of opportunities to develop leadership competencies. In this way, most emergent junior talents failed to use developmental lens to highlight any inherent difficulty, novelty, or 
size of the challenge in a different job that actually stretched or forced them to grow out of their comfort zone to acquire skills beyond the extant set. This failure was evident in the portfolio of one of the emergent junior talents as follows:

I was asked to stand-in as cashbook administrator when my colleague was on leave for a day. I was responsible for allocating payments from bank statement and transferring payments. These are critical areas in the business because I was dealing with debtors' collection and transferring of money to suppliers. In that month, our reporting system and month end was very smooth because of the quality of my work on that day (MDPP 9).

It is exceptional that one emergent junior talent highlighted the developmental power inherent in tasks she did as a stand-in which forced her to develop ability to communicate upwards:

Through job rotation I moved to [...] for a day. My colleague was off-duty. We are at the same level but he does reconciliations. This helped me expand my knowledge. It was a growth opportunity. It helped me improve my communication skills as I was talking to different senior managers in the business regarding signing off documents and payments... I had to sometimes answer several difficult questions to make the manager understand before he could sign off documents for payment to be made. I had to know my story very well. I realized that without good communication and attention to details, this job is very difficult. Communication of technical details was very important to do the task. It was not that easy, but a good and new opportunity to do a job different from mine (MDPP2).

\section{Conceptual Leadership Development}

Three of the emergent junior talents showed exclusively what they knew about leadership, rather than what they did to develop leadership, as well as how they evaluated their achievement of developmental goals in the given time period. Consequently, these participants did not put to test their leadership knowledge in an authentic context to use human capital as a basis to build social capital. In particular, one of the three emergent junior talents provided his conceptual understanding of leadership from existing literature (e.g. transformational leadership, leadership coaching, and leadership mentoring). Inevitably, this emergent junior talent lost the opportunity to make sense of new knowledge and create 
meaning for himself arising from feedback on implemented action, but also social influence or emotional impact that leadership interactions have on others.

In a slightly different way, another emergent junior talent used his repository of experiences and provided old evidence of what occurred a year before to describe how he had developed his leadership competencies. Precisely, evidence of conceptual leadership development was characterized by lack of participant`s initiative to try out activities in a social context to achieve a particular predetermined goal. Furthermore, there was no evidence of active reflection-in-action and also reflection-for-action to purposely contribute to on-

going improvement on any of the three leadership competencies that were deliberately selected as part of this program.

It was last year ... before this program ... I was attending to a customer who had a problem with [name of spare part was deleted]. I was alone. In these cases, I used to tell customers to call back or wait until the boss was in. We were making losses. But I know what my boss usually recommends in such cases. It is like you have a frame of reference. So one time, I made a decision, and reported to my boss when he returned. He was happy. I always refer to how my boss... and the others dealt with a similar problem in the past before I do anything. It is scary at first to make these decisions. But now, I do decide on my own on some matters. (MDDP13).

\section{Developing by Developing Others}

In this study, only one of the fifteen emergent junior talents perceived that he had developed his competence of leveraging diversity and building culture of collaboration through interpersonal understanding by training, monitoring, and supervising a colleague. In this way, he ultimately enhanced his own empathizing skills (e.g. putting self in the shoes of others) and relationship skills. Concisely, this emergent junior talent gave evidence of developing self by developing others through face-to face sharing of knowledge and spending time together with a colleague to help her gain hands-on experience. In the process of helping a colleague to gain access to and learn in a new job, this emergent junior talent became more aware of not only how people learn differently to ultimately internalize knowledge through practice, but also discovered unique differences or eccentricities about others. 
I have learnt that training and managing a colleague or people is not easy. Each individual is unique, different, and with different learning style which is different from mine. I needed to be patient with her, allow her to fully grasp what I was telling her as work inputs, processes, and allow her to see the outputs. She learnt the job when I adjusted to her pace of learning. We were all committed to do this. She wanted to excel while I wanted to stop doing this and concentrate on something. We spent three weeks together and I had to show her and also let her do the work to get the experience. We sometimes used the guide but there were lots of things that she had to learn by watching because they were not explained in the guide. I had to put myself in her shoes to understand that this was new and that one thing at a time was the best. Eventually, she was able to do the work on her own without me (MDPP 3).

Succinctly, the same participant wrote about his growing self-awareness in terms of his own unmet needs for development, but also discovering a variety of modes for his own development and value of interdependency in developing self.

I have developed ... but I do not think it's enough. I must be honest and admit that I don't think this one type of development activity has fully and completely developed me, helped to improve and develop myself much. I need to be trained myself through courses... and other people (MDPP 3).

\section{Discussion}

Predominantly, this study revealed that many of the emergent junior talents in this leadership development program experienced difficulties not only to lead themselves in a work environment which was unsupportive, but also failed to capture strong, dynamic, and complex process of how their leadership competencies actually developed over time. Notably, an emergent junior talent-in-transition also had difficulty to properly align the developmental power or effect of a repertoire of activities pursued or experiences on one hand and specific leadership competencies on the other.

In the light of these findings, it stands to logic to argue that assessment of leadership development should actually capture the complexity of the actual process of developing leadership as experienced by LDP participants. Drawing from this viewpoint, it is clear that leadership development is inherently difficult to assess fully and comprehensively partly because development occurs overtime. With focus on temporal dimension of development, 
Hannum, Martineau, and Reinelt (2007, p. 8) agree that "leadership development is a particularly complex process; it is not something that is fully knowable in a short period of time”. Time and complexity of leadership development process are some of the critical aspects in understanding leadership development. In a relatively long leadership development journey, reflective learning is cardinal for assessment of leadership development. However, reflection-as-learning may not be possible when participants have difficulties to identify and monitor key, evolving, and cumulative changes (e.g. shifts in sequence, dynamic changes in competence level, and across competences).

Providing evidence of a pattern of leadership competence development or developmental pathway and its trajectory and also continuously learn from identifying gaps in own behavior, skills, and attitude compared with the key criteria in respective competencies over a period of time is key to self-assess leadership development. Arguably, any use of portfolio assessment to understand leadership development is likely to be less valuable if participants are not able to critically reflect on their experiences. Bennis (1989, p. 98) argues that "there are lessons in everything, and if you are fully deployed, you will learn most of them. Experiences are not truly yours until you think about them, analyze them, examine them, question them, reflect on them, and finally understand them”.

Notably, emergent junior talent`s evidence in this LDP was not evolutionary to adequately weave through or fit snugly the various discrete or episodic activities to portray the process of leadership competence development or trail of various effects of developmental experiences on leadership competencies. Collins and Holton (2004, p. 218) illuminates that "while the variety of tasks and challenges encountered on the job are a major source of learning, the reality is that all jobs [, activities and experiences] are not developmentally equal, nor can they be expressed in an objective manner, which makes evaluation difficult”. Faced with this difficulty, emergent junior talents were preoccupied with mere portrayal of occasion, nature (e.g. stand-in, assignment, meeting etc.), and also duration rather than process of how each of the development opportunities were inherently stretching or demanding to induce acquisition of new competences or improvements in their set of competencies. Arguably, it is important from the viewpoint of development that these concrete experiences support and encourage LDP participants to reflect and learn from abstract concepts and test or retest them in new or different leadership context.

In essence, evidence of leadership development needs to not only capture what a participant is able to do, but also show understanding of what he or she could not do before. 
In reality, participants experienced challenges to self-assess the development of their leadership competences due to lack of self-monitoring and self-reflection on the criteria of leadership competencies. In this way, it was difficult to meaningfully gauge developmental progress on the competences over a period of time. It is also notable that emergent junior talents appeared to hold the view of leadership development as a series of disconnected, snapshot events to achieve relevant outcomes. In fact, leadership development is more of a process involving integrative effect of experiences to develop both individual and organization capacity to achieve greater, collective impact.

Diversity and complexity of evidence about the development of leadership competencies was also clearly undermined by lack of critical reflection on various key aspects of past activities or experiences in terms of their developmental contribution. In this way, the powerful learning cycle of "do it, reflect on it, revise, and try again” was not evident in the portfolios (Weindling, 2003, p. 8).

Ultimately, most of the evidence presented by emergent junior talent was weak and consequently failed to fully portray how leadership developed. Notably, evidence focused very much on effect of activities by emergent junior talents on collective or organizational level outcomes relating to business (e.g. improving their ability to contribute to business and change) and less on relational aspects (e.g. improving ability to relate to others) and personal leadership development. As participants focused on workplace evidence, there was no evidence on how their leadership developed in informal contexts. Cacioppe (1998) underscores that personal and family life are some of the contexts that provide an ideal place where people may safely test their leadership competencies (e.g. showing future direction, helping people cope with change, motivating and also inspiring others). Without evidence drawn from various contexts which include informal or contexts outside work, it is likely that leadership development by emergent junior talents in this LDP was actually not holistically captured in the portfolios.

From a leadership development design perspective, this pronounces that leadership development is not an event at all, but rather an on-going process grounded in personal development which is never complete and unfolds in both formal and informal contexts as well (Brungardt,1997; Weindling, 2003). As such, robust leadership development assessment should attempt to capture how "every form of growth or stage of development, and context ultimately promote, encourage, and assist the expansion of knowledge and expertise which 
optimizes leadership potential and performance” (Velsor, McCauley, \& Ruderman, 2010, p. 26).

With respect to developmental activities, duration and context, Cacioppe (1998, p. 48) is mindful that "a powerful component of leadership development involves hands-on, practical exercises or activities where participants have to solve problems, perform task or achieve results, often within a certain time frame”. Thus, leadership development needs to shape not only an interactive capacity to direct, align and secure commitment of people as a collective, but also focus on social influence and needs of individuals within a group (Weindling, 2003). Davis et al., (2005) corroborates that deliberate practice in real-world complexities and opportunities is significant to experiment leadership ideas and actions (e.g. demonstrate trust, respect to others, humility, and consideration for others. (Louw, Pearse, and Dhaya, 2012, p. 7) concur that "interaction with other individuals represents a key element in the development of social competencies which are central to leadership development".

Generally, most of the evidence in the portfolios focused on what emergent junior talents did to develop leadership. This resonates with the view that participants of a leadership development program need to cross the bridge from theory to leadership practice. Notably, few participants did not undertake any action on real issues, but demonstrated conceptual leadership development only. Understandably, conceptual knowledge requires intrapersonal work for leader development or expansion of a person's capacity to be effective in leadership roles and process. What is clear with these emergent junior talents is that they acquired human capital as individuals which resonate with leader development. Equally evident is the viewpoint that they did not develop or improve their social capital as they did not practice the relational and influencing complexity of leadership which is core to leadership development (Day, Harrison, \& Halpin, 2009). Nonetheless, Quatro, Waldman, and Galvin (2007) assert that conceptual leadership development is equally important as it helps leaders to have insights and construct vision over a time horizon, demonstrate intellectual stimulation to help followers get to the core of complex problems, and also think about the context in which a wide variety of stakeholders may be served as unique individuals but also as a collective. In advocating for the development of holistic leadership, they emphasizes that leadership development should not narrowly focus on specific aspects, but rather also develop analytical, conceptual, emotional, and spiritual domains of leadership. As such, leadership development needs to embrace different types of activities into a leadership development program (e.g. classroom-based learning, structured learning experiences and coaching or 
mentoring etc.) to purposely develop specific dimensions of leadership. In this respect, leadership development assessment needs to provide robust and grounded evidence that supports how these types of activities are effective in developing holistic leadership (Day \& Antonakis, 2012; Day, 2000)

It is unique that one emergent junior talent in this LDP developed by developing others. This resonates with the notion that effective leaders deal not only with their emotional and social needs, they also deal with those of others (Quatro, Waldman, \& Galvin, 2007). The fact that high-potential employees are developers or patient servants of others is interesting. Thus, while this emergent junior talent learnt about himself, he also discovered and capitalized on the differences in people to better support them to achieve their own mission. This study reveals that high potential employees are a powerful developmental vehicle for others while they meet their own needs. As only one of the fifteen emergent junior talents developed in this way, this reveals how the notion of serving others is not centralized as a leadership developmental opportunity. With this insight, the design of LDP and organizational internal environment needs to explore how this type of developmental opportunity can be deliberately included as part of how to develop future leaders who are servants or serve others.

Furthermore, this study revealed that while on-going support to enhance individual capacity of emergent junior talent is vital in a leadership development journey, there is a need to strike a balance between challenging and supporting them, but also affording them independence that does not trigger perceptions of being abandoned by the system or colleagues. It is imperative to mention that few of the emergent junior talents in this study used self-efficacy and self-monitoring to lead themselves on their leadership development journey when encountered by lack of support. The social learning theory by Bandura underscores that "self-assurance or self-efficacy is the strongest predictor of a person`s ability to set high goals, persist in the face of obstacles, to bounce back when reversals occur, and, ultimately to achieve the goals they set” (Buckingham, 2005, p. 10). Thus, nature and quality of leadership development program, and type of support provided by people and systems within the work environment are fundamentally not sufficient on their own, especially when individuals themselves simply lack intrinsic motivation or self-efficacy. As many people whose self-confidence was eroded during apartheid become part of the leadership pipeline, it is vital that personal mastery and self-efficacy be considered as critical aspects of support to them. 
From an organizational viewpoint, Quatro, Waldman, and Galvin (2007) points out that organizational context and what incumbent leaders reward or value sends strong messages to developing leaders and other employees about the importance or insignificance of various aspects of the organizational life. In this LDP, the unsupportive, organizational-wide mechanisms (e.g. performance and reward mechanism characterized by priority on competitive action and achievement of goals and rewards etc.) and the dysfunctional mentorship system (e.g. lack of meaningful developmental relationship; destructive or lack of feedback to mentees etc.) reflected the unspoken elements which retarded or impeded development of leadership within the organization. Predominantly, leadership development was also negatively impacted by lack of careful attention to the complex aspect of providing and receiving of feedback to enhance performance and self-efficacy. Some of the emergent junior talents were disempowered by dispassionately accurate understanding of the limits of their respective strengths or liabilities of their weaknesses through demeaning feedback from immediate managers. It is of primary importance that managers and mentors empower and support employees to lead themselves and others, while organizational mechanisms facilitate growth. Intuitively, portfolio assessment of leadership development is very appealing as a potential solution to how we assess development of LDP participants over time. However, this study concludes that most LDP participants experience various difficulties not only related to lack of critical reflection to unearth the process of leadership development, but also alignment of leadership developmental activities and pathways with their real effects on leadership competencies.

\section{Implications}

There are three implications of the findings of this study which relate to culture of leadership development, alignment of organizational systems to leadership development, and the challenge of consistent and critical reflection on criteria of leadership competence by LDP participants throughout the leadership journey.

Firstly, the various difficulties of emergent junior talents to lead themselves do not only reflect lack of self-efficacy, but also disabling patterns of activities and actions which were taken-for-granted in this LDP and organization as a whole. Undeniably, the corporate world has competing priorities, but these should not create obstacles to leadership development or socialize future leaders into a "lead self or sink world view" or legitimate the notion that high potential employees can be left to their own devices to develop leadership competencies. 
Inevitably, this poses a huge risk which has potential to culminate in high-performing employees being ill-prepared for future leadership. Inadvertently, this organization created or perpetuated low prioritization of any effort by employees to develop others on-the-job. Mindful of competing priorities in the business world, it is essential that leadership development practitioners use contextual opportunity and challenges to develop emergent junior talent that is not only fully aware of these competing priorities in organizations, but also able to balance them well and serve others.

Profoundly, this study highlights the caution that leadership practitioners should not harbor the illusion that organizational support to develop and sustain leadership competencies will materialize without addressing the research gap of understanding the role of organization culture in leadership development. It is equally prudent to join McDermott, Kidney, and Flood (2011, p. 359) in urging leadership development researchers to direct future research on leader's personal leadership development to illuminate the processes of developing the personal dimension of leadership which is missing in most research. This is salient as personal leadership development is a key social phenomenon that interacts with multiple cultural contexts which includes the organization to shape professional leadership development.

Secondly, organizational mechanism enhances or impedes what is being done to develop leadership, especially within the work environment. Kotter (1990a, b) is apt that well-led organizations tend to recognize and reward people who successfully develop leaders. In this study, organizational mechanisms were not properly aligned to leadership development efforts, resulting in lack of coherent system and shared responsibility for leadership development. Consequently, this made some of the participants to feel abandoned by both colleagues (immediate managers, mentors) and the unsupportive system in the organization. Leadership competence development may be enhanced by tightly and clearly linking the task of developing own leadership with that of supporting others to develop their leadership. Furthermore, leadership development researchers need to explore the role or impact of organizational systems in accelerating or decelerating how leadership competences develop over time. Despite enunciated support by the organization, not many LDP participants in this study were given support by their peers, immediate managers and mentors. Circumstances in the organization entrenched a relatively strong focus and recognition on achieving individual performance targets, than effort to develop leadership in others. Ultimately, this is what shaped, embedded and perpetuated the type and level of support given to LDP participants by 
others in the organization, but also signaled to employee what to prioritize and devote their time and energy on. Often, emergent junior talents were not supported by their respective mentors. While mentors are critical to develop the interpersonal realm of mentees, there is need to understand that they are also (e.g. employees) grappling with their own priorities, performance targets and rewards that they may not prioritize meeting with mentees or provision of constructive feedback. Mentoring is hard work and demands great emotional energy. As such, there is need for support to go beyond incentivizing mentors (e.g. recognition etc.), but also ensure that there is appropriate training and on-going support and conditions to energize a network of mentors in an organization to provide constructive feedback and also prepare mentees to receive and utilize it. Weiss and Molinari (2006) underscore 8 steps of an integrated approach to leadership which resonates with the findings of this study. Succinctly, these two authors advices on the need for a connection between leadership development and an organization's environmental challenges; fit between leadership development options and the culture of an organization; and that there is a balance of enterprise-wide needs with local needs. All these resonate explicitly with the findings in this study. It is noteworthy that leadership development in post-apartheid South Africa requires a comprehensive strategy for integrated leadership development, nurturing context for development to occur, and also a focus on individual needs, especially of those whose self-confidence and efficacy was battered by apartheid.

Lastly, the emergent junior talents faced the challenge of consistently reflecting on leadership competence criteria to uncover actual development during the leadership development journey. This study concludes that LDP participants' good understanding of leadership competencies alone is inadequate for them to self-assess their leadership development. In using portfolio to assess leadership development, it is necessary that leadership development practitioners underscore critical self-reflection by participants in order to see evidence of their leadership development or lack of it along the leadership development journey. Future research should explore how evaluative and reflective capacity of leadership development participants affects the evidence of their actual development which they present in a portfolio.

\section{References}

Avolio, B. J., \& Chan, A. (2008). The dawning of a new era for genuine leadership development. In G. P. Hodgkinson \& J. Kevin. Ford (Eds.), International review of industrial and organizational psychology (pp. 197-238). Chichester: John Wiley. 
Avolio, B. J., Walumbwa, F. O., \& Webber, T. J. (2009). Leadership: Current theories, research, and future directions. Annual Review of Psychology, 60, 421-449.

Baltes, P. B., \& Staudinger, U. M., Lindenberger, U. (1999). Life span psychology: Theory and application to intellectual functioning. Annual Review of Psychology, 50(1), 471-507.

Bell, B. S., \& Federman, J. E. (2010). Self-Assessments of knowledge: Where do we go from here? Academy of Management Learning \& Education, 9(2), 342-347.

Benjamin, B., \& O’Reilly, C. (2011). Becoming a Leader: Early career challenges faced by MBA graduates. Academy of Management Learning \& Education, 10(3), 452-472.

Bennis, W. (1989). On becoming a leader. New York: Addison-Wesley.

Bolden, R., \& Gosling, J. (2006). Leadership competencies: Time to change the tune. Leadership, 2(2), 147-163.

Borko, H., Michalec, P., Timmons, M., \& Sidle, J. (1997). Student teaching portfolios: A tool for promoting reflective practice. Journal of Teaching Education, 48(5), 347-357.

Boyatzis, R. E. (1982). The competent manager: A model for effective performance. New York: John Wiley \& Sons.

Brungardt, C. (1997). The making of leaders: A review of the research in leadership development and education. The Journal of Leadership Studies, 3(3), 81-95.

Buckingham, M. (2005). What do great managers do? Harvard Business Review, 83(3), 70-79.

Cacioppe, R. (1998). An integrated model and approach for the design of effective leadership development programs. Leadership \& Organization Development Journal, 19(1), 44-53.

Carden, L. L., \& Callahan, J. L. (2007). Creating leaders or loyalists? Conflicting identities in a leadership development program. Human Resource Development International, 10(2), 169-186.

Charan, R., Drotter, S., \& Noel, J. (2001). The leadership pipeline: How to build the leadership powered company ( $2^{\text {nd }}$ ed.). San Francisco, CA: Jossey-Bass.

Chung-Herrera, B. G., Enz, C. A., \& Lankau, M. J. (2003). Grooming future hospitality leaders: A competencies model. Cornell Hotel and Restaurant Administration Quarterly, 44(3), 17-25.

Collins, D. B., \& Holton, E. F. (2004). The effectiveness of managerial leadership development programs: A meta-analysis of studies from 1982 to 2001. Human Resource Development Quarterly, 15(2), 217-248.

Conger, J. A., \& Fulmer, R. (2005). Developing your leadership pipeline. Harvard Business Review, 81(12), 76-84.

Davis, S., Darling Hammond, L., LaPointe, M., \& Meyerson, D. (2005). School leadership study: Developing successful principals. Palo Alto: Stanford Educational Leadership Institute.

Day, D. V. (2000). Leadership development: A review in context. The Leadership Quarterly, 11(4), 581-613.

Day, D.V. (2010). The difficulties of learning from experience and the need for deliberate practice. Industrial and Organizational Psychology, 3(1), 41-44.

Day, D. V., \& Antonakis, J. (2012). The nature of leadership (2 ${ }^{\text {nd }}$ ed.). Thousand Oaks, CA: Sage Publication.

Day, D. V., Harrison, M. M., \& Halpin, S. M. (2009). An integrative approach to leader development: Connecting adult development, identity, and expertise. New York: Routledge.

Dixon, N. M. (1993). Developing managers for the learning organization. Human Resources Management Review, 3(3), 243-254.

Driessen, E. W., Van Tartwijk, J., Vermunt, J. D., \& Van Vleuten, C. P. M. (2003). Use of portfolios in early undergraduate medical training. Medical Teacher, 25(1), 18-23.

Eva, K., \& Regehr, G. (2008). I'll never play professional football and other fallacies of self-assessment. The Journal of Continuing Education in the Health Professions, 28(1), 14-19.

Freedman, A. M. (2011). Some implications of validation of the leadership pipeline concept: Guidelines for assisting managers- in-transition. The Psychologist-Manager Journal, 14(2), 140-159.

Gordon, J. (2003). Assessing students' personal and professional development using portfolios and interviews. Medical Education, 37(4), 335-340.

Hannum, K. M., Martineau, J. W., \& Reinelt, C. (2007). The handbook of Leadership Development Evaluation. San Francesco, CA: Jossey-Bass.

Jauhari, V. (2006). Competencies for a career in the hospitality industry: An Indian perspective. International Journal of Contemporary Hospitality Management, 18(2), 123-134. 
Kaiser, R. B. (2011). The leadership pipeline, fad, fashion, or empirical fact? An introduction to the special issue. The Psychologist-Manager Journal, 14(2), 71-75.

Kaiser, R. B., \& Craig, S. B. (2011). Do the behaviors related to managerial effectiveness really change with organizational level? An empirical test. The Psychologist-Manager Journal, 14(2), 92-119.

Kaiser, R. B., Craig, S. B., Overfield, D. V., \& Yarborough, P. (2011). Differences in managerial Jobs at the bottom, middle, and top: A review of empirical research. The Psychologist-Manager Journal, 14(2), 76-91.

Kolb, D. A. (1984). Experiential learning: Experience as the source of learning and development. Englewood Cliffs, NJ: Prentice-Hall.

Kotter, J. P. (1990a). What leaders really do? Harvard Business Review, 68, 103-111.

Kotter, J. P. (1990b). A force for change: How leadership differs from management. New York: Free Press.

Louw, L., Pearse, N. J., \& Dhaya, J. (2012). The role of experience in the development of social competencies. South African Journal of Human Resources Management, 10(1), 1-9.

Mallik, M. (1993).Theory-to-practice links. Senior Nurse, 13(4), 41-46.

Manderscheid, S. V. (2008). New leader assimilation: An intervention for leaders in transition. Advances in Developing Human Resources, 10(5), 686 -702.

Mann, K. V. (2010). Self-assessment: The complex process of determining 'How We Are Doing'-A perspective from medical education. Academy of Management Learning \& Education, 9(2), 305-313.

McCauley, C. D., Moxley, R. S., \& Van Velsor, E. (1999). The center for creative leadership handbook of leadership development. San Francisco: Jossey-Bass.

McDermott, A., Kidney, R., \& Flood, P. (2011). Understanding leader development: Learning from leaders. Leadership and Organization Development Journal, 32(4), 358-378.

McMullan, M. (2006). Students' perceptions on the use of portfolios in pre-registration nursing education: A questionnaire survey. International Journal of nursing Studies, 43(3), 333-343.

McMullan, M., Endacott, R., Gray, M. A., Jasper, M., Miller, C. M. L., Scholes, J., \& Webb, C. (2003). Portfolios and assessment of competence: A review of literature. Journal of Advanced Nursing, 41(3), 283-294.

Mittendorff, K., Jochems, W., Mijers, F., \& Brok, P. D. (2008). Differences and similarities in the use of portfolio and personal development plan for career guidance in various vocational schools in the Netherlands. Journal of Vocational Education and Training, 60(1), 75-91.

Moskal, B. M. (2010). Self-assessments: What are their valid uses? Academy of Management Learning \& Education, 9(2), 314-320.

Mulder, M., Weigel, T., \& Collins, K. (2006). The concept of competence concept in the development of vocational education and training in selected EU member states: A critical analysis. Journal of Vocational Education and Training, 59(1), 65-85.

Quatro, S. A., Waldman, D. A., \& Galvin, B. M. (2007). Developing holistic leadership: Four domains for leadership development and practice. Human Resource Management Review, 17(4), 427-441.

Ready, D., \& Conger, J. (2003). Why leadership-development efforts fail. MIT Solan Management Review, 44(3), 83-88.

Redman, W. (1994). Portfolios for development: A guide for trainers and managers. London: Kogan Page.

Revans, R.W. (1983). The ABC of action learning. Bromley: Chartwll-Bratt.

Sparrow, P. (2002). To use competencies or not to use competencies? That is the question. In M. Pearn (Eds.). Individual differences and development in organizations (pp. 107-129). London: Wiley.

Van Velsor, E., McCauley, C. D., \& Ruderman, M. N. (2010). The center for creative leadership handbook of leadership development ( $3^{\text {rd }}$ ed.). San Francisco, CA: Jossey-Bass.

Weindling, D. (2003). Leadership development in practice: Trends and innovations. Nottingham, UK: National College for School Leadership.

Weiss, D., \& Molinari, V. (2006). Integrated leadership development. Industrial and Commercial Training, 38(1), 3-11.

Zaccaro, S. J. (2001). The nature of executive leadership: A conceptual and empirical analysis of success. Washington, DC: American Psychological Association. 